This item was submitted to Loughborough's Research Repository by the author.

Items in Figshare are protected by copyright, with all rights reserved, unless otherwise indicated.

\title{
Seeing you seeing me: Stereotypes and the stigma magnification effect
}

PLEASE CITE THE PUBLISHED VERSION

https://doi.org/10.1037/apl0000060

PUBLISHER

(c) American Psychological Association 2018

VERSION

AM (Accepted Manuscript)

PUBLISHER STATEMENT

This work is made available according to the conditions of the Creative Commons Attribution-NonCommercialNoDerivatives 4.0 International (CC BY-NC-ND 4.0) licence. Full details of this licence are available at: https://creativecommons.org/licenses/by-nc-nd/4.0/

\section{LICENCE}

CC BY-NC-ND 4.0

\section{REPOSITORY RECORD}

Mikolon, Sven, Glen E. Kreiner, and Jan Wieseke. 2019. "Seeing You Seeing Me: Stereotypes and the Stigma Magnification Effect”. figshare. https://hdl.handle.net/2134/33446. 


\title{
Seeing You Seeing Me: \\ Stereotypes and the Stigma Magnification Effect
}

\begin{abstract}
Despite an increased interest in the phenomenon of stigma in organizations, we know very little about the interactions between those who are stigmatized and those who stigmatize them. Integrating both the perceptions of the stigmatized worker and the stigmatizing customer into one model, the present study addresses this gap. It examines the role of stereotypes held by customers of stigmatized organizations and metastereotypes held by the stigmatized workers themselves (i.e., their shared beliefs of the stereotypes customers associate with them) in frontline exchanges. To do so, data regarding frontline workers (vendors) of homeless-advocate newspapers from 3 different sources (vendors, customers, trained observers) were gathered. Multilevel path-analytic hypotheses tests reveal (a) how frontline workers' prototypicality for a stigmatized organization renders salient a stigma within frontline interactions and (b) how stereotypes by customers and metastereotypes by frontline workers interact with each other in such contacts. The results support a hypothesized interaction between frontline workers' metastereotypes and customers' stereotypes-what we call the "stigma magnification effect". The study also derives important practical implications by linking stigma to frontline workers’ discretionary financial gains.
\end{abstract}

Keywords: frontline workers, prototypicality, stigma, stereotypes, metastereotypes 
A stigma is deeply discrediting and involves being the target of negative stereotypes, being discriminated against, or even being rejected (Crocker, Major, \& Steele, 1998). Workplacerelated stigma has been studied in a variety of contexts—-from stigmatized work (e.g., Ashforth, Kreiner, Clark, \& Fugate, 2007) to stigmatized workers (e.g., Babin, Boles, \& Darden, 1995). Although a stigma is inherently problematic for any worker, it is particularly detrimental for sales or service representatives because as part of their boundary spanning role these frontline employees regularly interface with customers (Adams, 1976). Their job performance and personal well-being thus depend in large part on favourable interactions with customers (Adams, 1976; Ahearne, Bhattacharya, \& Gruen, 2005; Chebat \& Kollias, 2000). In addition to this practical relevance, understanding stigma dynamics among frontline employees also provides a window into an important theoretical process - the way in which the stigmatizer and the stigmatized interact.

Indeed, although there has been an increased interest in the phenomenon of stigma in organizations in recent years (e.g., Devers, Dewett, Mishina, \& Belsito, 2009; Hudson \& Okhuysen, 2009; King, Shapiro, Hebl, Singletary, \& Turner, 2006; King, Shapiro, Hebl, Singletary, \& Turner, 2006; Paetzold, Dipboye, \& Elsbach, 2008; Vergne, 2012; Warren, 2007), we still lack a deep understanding about how a stigma plays out in interactions between stigmatized boundary spanners and their clients. This is largely due to the unidirectional focus adopted by past research in analyzing the phenomenon of stigma in customer-employee interactions (e.g., Cowart \& Brady, 2014; Hekman et al., 2010; King et al., 2006; Lee, Sandfield, \& Dhaliwal, 2007). As a consequence, current explanations for how stigma plays out in such interactions have focused on either the negative or aversive reactions to a stigma by the perceiver or on the negative psychological and practical effects for the stigmatized individual (e.g., Hekman et al., 2010; King et al., 2006; Lee et al., 2007). However, since Goffman’s (1963) seminal work we know that stigma inherently involves 
interactions between two or more parties. Thus, unidirectional approaches are akin to studying only one dancer in a duet, rather than looking at the synergies and interdependencies between the two dancers. Indeed, in his pioneering work on stigma, Goffman (1963) argued that "the causes and effects of stigma must be directly confronted by both sides" (p. 12). Thus, the adverse social consequences of stigma are in fact likely to be cocreated from both the perceiver and the bearer. Therefore, the unidirectional focus of past research is a considerable limitation because it has prevented scholars from exploring how the negative social consequences of stigma are both instigated by the stigmatizers and those bearing the stigma themselves. Such an understanding would provide a more holistic picture of how a stigma impacts frontline employees’ job performance and would help to consider new ways to alleviate the negative effects of the stigma.

In the present study we consider both the stigmatized frontline worker and the customer in the same model. Conceptualizing and testing such a model allows us to account for interdependent stigmatization effects during customer-employee interactions. More specifically, we conceptually derive and empirically test what we term the "stigma magnification effect,” that is, a phenomenon occurring within the context of social interactions in which stigmatized individuals often unwittingly reinforce others' negative reactions toward them. We propose that this magnification results from two cognitive processes: (a) as negative stereotypes become activated when stigma is perceived in a stigmatized frontline worker (Blascovich, Mendes, Hunter, \& Lickel, 2000) and (b) as negative metastereotypes (group members' shared beliefs about the stereotypes others associate with their group) become activated when a stigmatized frontline worker perceives a customer (Frey \& Tropp, 2006). Furthermore, we aim to shed light on how an organizational stigma is made salient in customer-employee interactions and reveal the pivotal role of 
frontline workers’ prototypicality for a stigmatized organization in triggering stigmatization by the customers.

For the purposes of this study, we studied the frontline employees of two stigmatized organizations that sell "homeless-advocate street newspapers"-newspapers that are sold often (though not exclusively) by homeless individuals. The organizations are stigmatized because as a central element of their missions they employ the homeless (cf. Kreiner, Ashforth, \& Sluss, 2006). Most notably however, roughly only one third of the employed frontline workers are actually homeless. We argue that all of the frontline employeesincluding the nonhomeless_-acquire a stigma through being perceived as prototypical representatives of their organization. We collected data from multiple sources to capture the complexities and nuances of customer-employee interactions; this included data from the vendors themselves, vendors' customers and noncustomers, and trained interviewers who observed the interactions between these vendors and their potential and actual customers. The present research extends our current understanding of stigma in several important ways. First, situating stigma in an integrated framework of frontline workers' and customers' negative stereotypes, we contribute to the stigma literature by offering a novel explanation for how a stigma becomes salient and subsequently poisons frontline interactions. More specifically, we reveal that the negative adverse effects of stigma in customer-employee interactions are actually coproduced by the stigma bearer and perceiver because stigmatized frontline employees unwittingly reinforce negative stereotypes toward them through what we term the "stigma magnification effect." This insight is important because it moves our knowledge beyond existing unidirectional explanations and helps us to understand how the stigma phenomenon is related to the perceptions of both frontline employees and customers.

Second, we reveal one of the key drivers of the stigma magnification effectorganizational prototypicality—-through which frontline workers reflect the stigma of their 
organization. A novel insight of our study, then, is that an organizational stigma will become activated in customers' minds as a function of frontline workers' organizational prototypicality. Our research thus reveals some of the implications of organizational stigma for employees and affiliates.

Furthermore, our finding that organizational prototypicality instigates stigmatization advances more general research on stigma in customer-employee interactions. This stream of research has predominantly focused on the outcomes of stigma, rather than on the antecedents, and has solely studied stigma originating from personal and social categories, such as minority-group status or obesity (Cowart \& Brady, 2014; Hekman et al., 2010; King et al., 2006). As such, our finding reveals that there are systematic as opposed to random differences in the activation of an organizational stigma in customer-employee interactions. Therefore, given that the perception of organizational prototypicality can be altered or influenced, unlike the more fixed characteristics of many stigmatized individuals, our finding opens an important door into managing the triggers of stereotyping and stigmatization. Finally, by linking stigma to frontline workers' discretionary financial gains we highlight the high relevance of stigma for research and practice in boundary-spanning contexts.

\section{Conceptualizing Frontline Workers’ Stigma}

The term stigma originates from the Greek language and initially referred to bodily signs designed to expose something unusual and bad about the moral status of the signifier (Goffman, 1963). In social psychology, a stigma has typically been defined as belonging to a social category, against which others collectively hold negative stereotypes and beliefs (Crocker \& Major, 1989). In this sense, a stigma is socially constructed and collectively shared (Devers et al., 2009). Stigmatized entities are on the receiving end of negative stereotypes that convey characteristics, attributes, or behaviors that pose a threat to the vitality of individuals, groups, or society at large (Crocker \& Major, 1989; Crocker et al., 
1998; Stangor \& Crandall, 2000). Accordingly, members of stigmatized categories are viewed as possessing characteristics that promote a threat to society in the way that they threaten concrete goods, such as health, safety or social position and on a more abstract level values, beliefs, social or moral orders (Ashforth \& Kreiner, 1999; Schaller \& Conway, 1999; Stangor \& Crandall, 2000).

\section{Sources of Stigma for Frontline Workers}

Frontline employees can become stigmatized for a multitude of reasons_-because of their ethnicity, social class, sexuality, gender, physical disability, religion, or even because of the occupation or organization they work for (Adkins \& Swan, 1982; Babin et al., 1995; Lee

et al., 2007; cf. Ashforth \& Kreiner, 1999; Kreiner et al., 2006). Based on these findings, three categories can be distilled from which frontline workers can acquire a stigma-from the organization they represent (e.g., “core stigmatized” companies; Hudson \& Okhuysen, 2009), from their occupation (e.g., “dirty work” jobs, Ashforth \& Kreiner, 1999), or from their personal social categories (e.g., gender or ethnicity, Crocker et al., 1998).

For frontline workers, a particularly important—yet overlooked by quantitative empirical research—social category from which they can acquire a stigma is the organization that they represent. Because organizational stigmata are contagious, they tend to generalize from the organization to the broader social category, such that they sometimes encompass everyone associated with the organization (Wiesenfeld, Wurthmann, \& Hambrick, 2008). In this case the person is "obliged to share some of the discredit of the stigmatized" (Goffman, 1963, p. 30). Frontline workers of stigmatized organizations face the challenge of stigma contagion rather acutely. In boundary spanning interactions, frontline workers are the "face" of an organization (Hartline, Maxham, \& McKee, 2000) and are likely to absorb the stigma of their organization because customers categorize boundary spanners in terms of their organizational affiliation. As a result, it is likely that negative consequences of stigmatization 
become apparent not only at the organizational level but also at the level of boundary spanning interactions.

\section{Theoretical Model and Hypotheses Model Overview}

To fully articulate the conceptual underpinnings of our model, we integrate the literature on stigma with research on three important constructs—prototypicality, stereotypes, and metastereotypes — that are each phenomenologically linked to stigma. Figure 1 provides an overview of the proposed hypotheses (additional covariates are described in the method section). To preview the context of our study, we note that the focal employees are vendors of two stigmatized organizations that sell "homeless-advocate street newspapers"-newspapers that are sold often (though not exclusively) by homeless individuals. These vendors interact in sales encounters with actual and potential customers, but for reasons of simplicity we will refer to them as customers.

Insert Figure 1 about here

\section{Stigmatization in Frontline Interactions: Negative Stereotypes and Metastereotypes}

The application of negative stereotypes to members of dubious social categories is at the heart of stigmatization processes. Members of stigmatized categories, in turn, develop metastereotypes - shared beliefs of the negative stereotypes that others commonly associated with their own category (for reviews, see Frey \& Tropp, 2006; Major \& O’Brien, 2005). Like two sides of the same coin, negative stereotypes and negative metastereotypes reflect the perspective of the stigmatizing customer and the stigmatized employee. Both concepts, however, have hitherto not been linked together in an empirical study on customer-employee interactions, leaving our understanding quite incomplete.

Negative stereotypes-The customer's perspective. Stigmatized entities are on the receiving end of negative stereotypes that convey characteristics, attributes, or behaviors that pose a threat to the vitality of individuals, groups, or society at large (Crocker \& Major, 1989; 
Crocker et al., 1998; Stangor \& Crandall, 2000). Stereotypes have been defined as often overgeneralized, rigid, and exaggerated beliefs about the characteristics, attributes, and behaviors of members of certain groups (Hilton \& von Hippel, 1996; Krueger, Hall, Villano, \& Jones, 2008). When an individual encounters a prototypical exemplar of a stigmatized category, such as a customer encountering a prototypical frontline worker of a stigmatized organization, negative stereotypes, which are attached to the stigmatized social category, become activated in the customers' mind and subsequently guide perception (Biernat \& Dovidio, 2000; Stangor \& Crandall, 2000). These stereotypes evoke a specific, threatening set of characteristics and often include an exaggerated sense of danger (Herek, Capitanio, \& Widaman, 2002; Pryor, Reeder, Monroe, \& Patel, 2010). As a consequence, they bias perceivers' perception and can even lead them to interpersonally reject and socially discriminate against members of the stigmatized social category in question (Hebl \& Dovidio, 2005). This would imply devastating adverse consequences for the quality of customer-employee interactions.

Negative metastereotypes-The frontline employee's perspective. Members of stigmatized groups have shared beliefs of the negative stereotypes that others commonly associate with their group (for reviews see Frey \& Tropp, 2006; Major \& O’Brien, 2005). Vorauer, Main, \& O’Connell (1998) termed these shared beliefs metastereotypes—what a group believes others think about them. Metastereotypes are conceptually distinct from selfstereotypes (Hogg \& Turner, 1987) in that metastereotypes refer to individual group members' beliefs about how their group is viewed by others, whereas self-stereotypes refer to individuals’ own personal beliefs about their group (Vorauer et al., 1998). Metastereotypes are predominantly negative in their content (Frey \& Tropp, 2006; Vorauer et al., 1998). They become activated in interactions because members of stigmatized groups anticipate that they will be categorized and therefore treated in terms of their group membership. In fact, social 
psychological research has revealed that members of stigmatized groups are particularly likely to be conscious of how out-group members think about them in terms of the stereotypic attributes that they think are ascribed to their group (Branscombe, Ellemers, Spears, \& Doosje, 1999; Frey \& Tropp, 2006; Méndez, Gómez, \& Tropp, 2007). For instance, individuals in dirty work jobs such as abortion providers, used car sales people, and exotic entertainers report firmly held beliefs that outsiders such as clients often view them as "bad" and/or “immoral” merely because of their job (Ashforth et al., 2007). Indeed, this anticipation has been shown to persist even when the stigma in fact has no effect on the treatment the stigmatized receives (Kleck \& Strenta, 1980; Major \& Crocker, 1993). Thus, metastereotypes often guide stigmatized frontline workers' perceptions during the course of their interactions with out-group members, including potential customers (Vorauer et al., 1998).

\section{Stigmatization and Prototypicality for a Stigmatized Category}

Frontline workers' prototypicality can be defined as the degree to which a frontline worker is exemplary for an organization (cf. van Kleef, Steinel, \& Homan, 2013). Frontline workers are said to be highly prototypical for their organization when they signal the attributes, behaviors and orientations that are specific to the respective organization via verbal expressions, behaviors, dress or other tangibles to the customers (Ahearne et al., 2005;

Bitner, 1990; Homburg, Wieseke, \& Hoyer, 2009; Latrofa, Vaes, Cadinu, \& Carnaghi, 2010; Sluss, Ployhart, Cobb, \& Ashforth, 2012). Prototypicality for a stigmatized category plays a pivotal role in the activation of stigma-related stereotypes in the mind of perceivers. From a theoretical stance, the link between prototypicality and stereotype activation draws from research in social categorization and stereotyping. This stream of research thoroughly documents that perceivers of a social category are most likely to rely on stereotypes for information processing when there is a high fit between the stereotypes that are attached to a category and the available information from a stimulus (for reviews, see Macrae \& 
Bodenhausen, 2000; van Knippenberg \& Dijksterhuis, 2000). Thus, in the eyes of the perceiver, prototypical group members serve as a particularly vivid and unambiguous cue for social categorization because they quintessentially represent that for which the category stands. As a result, when a stimulus is highly prototypical for a category, people classify the stimulus in terms of this category and assume that the stimulus carries the category's inferred attributes (Macrae \& Bodenhausen, 2000). Once activated, these stereotypes guide perception and subsequently lead perceivers to stigmatize the category-member.

Organizational prototypicality and stereotypes. This evidence suggests that frontline workers' reflection of an organizational stigma in social interactions is a function of their organizational prototypicality. Although being prototypical might be beneficial for the individual frontline employee when customers predominantly associate positive attributes with the organization (cf. Wentzel, 2009), prototypicality will likely be harmful when the organization is stigmatized, prototypicality will render the stigma psychologically salient to both the employee and the customer during the encounter. The more prototypical that frontline employee is for a specific organization, the more they quintessentially represent what the organization stands for and as a result, the more they are judged on the basis of their organizational affiliation. It follows, then, that frontline employees who are highly prototypical for their stigmatized organization will trigger negative stigma-related stereotypes in the minds of customers. Therefore, we hypothesize:

Hypothesis 1 (H1): Higher frontline workers' organizational prototypicality will trigger customers' negative stereotypes more strongly.

Organizational prototypicality and metastereotypes. As noted above, metastereotypes reflect group members' shared beliefs about the stereotypes that others associate with their stigmatized group. Theoretical support for the link between prototypicality and metastereotypes can be found in the social identity and social categorization literatures (Abrams \& Hogg, 2004; Hogg, 2003). Individuals who are highly 
prototypical for their own group are more likely to think of themselves as group members rather than as unique individuals (Spears, Doosje, \& Ellemers, 1997). Thus, highly prototypical frontline employees therefore might more readily believe that customers think in terms of their organizational affiliation and the corresponding stereotypical attributes about them. Similarly, compared with less prototypical group members, highly prototypical group members are likely to sense that they strongly reflect the group to perceivers. As a consequence, highly prototypical group members more than low prototypical group members expect to be judged on the basis of the stereotypes that they think others assign to their group (Frey \& Tropp, 2006; Jost \& Banaji, 1994) rather than on their idiosyncratic characteristics (Frey \& Tropp, 2006). In essence, one’s own perception of prototypicality for the group implies an increased likelihood to believe that others will also perceive that prototypicality. It follows, then, that prototypical group members are particularly prone to rely on metastereotypes to infer how they are perceived. In sum, this reasoning leads to the following hypothesis:

Hypothesis 2 (H2): Higher frontline workers' organizational prototypicality will lead to stronger frontline workers' metastereotypes.

\section{Perceived Quality of Interaction}

It is thoroughly acknowledged in marketing research that successful selling episodes have to be properly managed by both the seller and the buyer (Crosby, Evans, \& Cowles, 1990; Ma \& Dubé, 2011; Solomon, Surprenant, Czepiel, \& Gutman, 1985). As such, a service or sales interaction represents an interaction between a customer (or a potential customer) and a service provider in which resulting outcomes are mutually influenced by both actors (Voss, Roth, Rosenzweig, Blackmon, \& Chase, 2004). Paralleling these findings in marketing, research in social psychology has revealed that the psychological consequences of stigmatization are prevalent in human interactions (e.g., Blascovich et al., 2000; Hebl, Tickle, \& Heatherton, 2000). Further, research has also highlighted the importance of studying the 
responses of both the perceiver and the bearer to understand stigmatization effects (e.g., Biernat \& Dovidio, 2000). In our context, there are important implications of this for the perceived quality of interaction, which can be formally defined as a judgment about an overall excellence or superiority of a customer-employee interaction (cf. Doucet, 2004; Parasuraman, Zeithaml, \& Berry, 1988). Specifically, we argue that business interactions between frontline employees working for a stigmatized organization and customers (and noncustomers) are tainted and hence perceived quality of interaction is mutually undermined.

The influence of stereotypes on perceived quality of interaction. We predict that perceived quality of interaction of a service encounter will be judged more negatively by customers holding negative stereotypes against frontline workers than by customers with less strongly held stereotypes. Theoretical support for this contention comes from research in social categorization (Macrae \& Bodenhausen, 2000). This stream of research maintains that once stereotypes become activated in a perceiver's mind, they shape perception of subsequently encountered information through selective attention and selective interpretation (cf. Doucet, 2004). Selective attention is triggered because stereotypes provide expectancies about out-group members that direct attention and filter experience (Macrae \& Bodenhausen, 2000). This, in turn, leads perceivers to emphasize stereotype-consistent information (Macrae, Stangor, \& Milne, 1994). Selective interpretation arises because cognitive capacities are generally taxed and stereotypes function as cognitive economizers (Wilder, 1993). As stereotypeconsistent information tends to be processed with less cognitive capacity and therefore more rapidly (Macrae \& Bodenhausen, 2000), activated stereotypes lead to an information-processing advantage for stereotype-consistent information (e.g., Fiske, 1998; Fyock \& Stangor, 1994; Macrae et al., 1994). Hence, through this processing strategy, stereotype-consistent information is more likely to be interpreted and remembered and stereotypeinconsistent information is likely to be screened out. As a major consequence, 
memory is substantially more biased and stereotypic than in the absence of activated stereotypes (Brickson \& Brewer, 2001; Macrae \& Bodenhausen, 2000). Applied to the present context, this evidence suggests that customers who harbor negative stereotypes toward a frontline worker are predisposed toward the others' stigma. As a consequence, attention to negative, stereotype consistent aspects of the interaction is enhanced and shifted away from stereotypeinconsistent information. Therefore, customers’ perceptions of interaction quality will be negatively biased. In fact, also following a social categorization perspective, Ashforth and Humphrey (1997) argue in their analysis of organizational labeling processes that in service encounters, social actors will interpret information in a way to confirm the initial label or stereotype. Hence:

Hypothesis 3 (H3): Stronger negative customer stereotypes will lead to decreases in the perceived quality of interaction.

The moderating role of metastereotypes: The stigmamagnification effect. When stigmatized group members hold strong metastereotypes, they expect to be negatively evaluated in terms of the stereotypes that they believe others associate with their group (Vorauer et al., 1998). This expectation leads to uncertainty about how one should behave and interact with members of other groups (Frey \& Tropp, 2006). This uncertainty arises because of two simultaneous tensions: individuals strive to not fulfill negative stereotypes about their own group (Steele \& Aronson, 1995), and yet those individuals are not clear about what behaviors are necessary to avoid being negatively stereotyped (Vorauer, Hunter, Main, \& Roy, 2000). Therefore, frontline workers may be uncertain about how they should best interact with others in performing their boundary spanning role (Hartline \& Ferrell, 1996). As a consequence, stigmatized frontline workers’ may react less relaxed (Devine, Evett, \& Vasquez-Suson, 1996) and unwittingly display nonverbal behaviors that indicate negative responses to the interaction, such as increased fidgeting (Dovidio, 2001; Frey \& Tropp, 2006). Although these behaviors might be ambiguous in their own right, in the context of a 
customer-employee interaction, the customer must interpret them in some way-even if nonconsciously — as they make sense of the new situation. If the customer already harbors a strong negative stereotype against the frontline worker, these behaviors will more likely be interpreted negatively. This negative interpretation can then have further detrimental effects on how the interaction experience is perceived. Hence, it follows that frontline employees' metastereotypes will enhance the negative effect of stereotypes on customers’ perceived quality of interaction. We term this the "stigma magnification effect" and hypothesize: Hypothesis (H4): Frontline workers' metastereotypes will moderate the negative effect of customers' negative stereotypes on their perceived quality of interaction, such that the negative effect will be enhanced with more strongly held metastereotypes.

The influence of perceived quality of interaction on customer rewards. When interfacing with customers, frontline workers try to create a favorable interaction experience for their customers in exchange for financial gains (Chi, Grandey, Diamond, \& Krimmel, 2011). In this regard, existing research shows that favorable customer assessments of interactions with frontline workers can result in increased customer rewards such as tip sizes (Lynn, 2003; Lynn \& McCall, 2000). From a theoretical perspective, it can be argued that the concept that drives customer rewards is customer value, defined as a customer's assessment of the value that has been created for him or her, which includes a trade-off between all relevant benefits and sacrifices associated with the interaction (Homburg, Wieseke, \& Bornemann, 2009). As customer value can be created by fulfilling customer needs regarding the exchange process itself (Szymanski, 1988), favorable assessments of quality of interaction will lead to a higher customer value. Given that customer value captures a customer's perceived worth of the interaction in money, it follows that:

Hypothesis 5 (H5): Higher perceived quality of interaction will lead to increased customer rewards.

\section{Method}

\section{Organizational Context}


We studied vendors of homeless-advocate street newspapers. These newspapers, published in dozens of large cities in North America and Europe, are published with the goal of helping homeless and other disadvantaged individuals. The newspapers are produced monthly by professional journalists and cover local, cultural, and sociopolitical topics. Some articles focus on the plight of homeless individuals and societal policies toward the homeless, but the majority of articles are written on broader topics of interest to the wider readership of city residents, and the papers strive to avoid polarizing political issues (to appeal to a wider audience). Two organizations that publish these newspapers in two large European cities agreed to participate in our study. Both organizations are very well-known among the populace and in the cities they are distributed in (as indicated by several reports in popular press and by our conversations with organizational members, leaders, and customers) as providing a source of income for homeless people; both organizations are comparable as there are no differences in routines or structures. The vendors of the newspapers are officially accredited by the organizations; they receive an official vendor ID and then they are allowed to sell the street newspapers. Vendors first buy the papers themselves from the organizations and then sell them for a higher price to people on the street. All vendors can contact social workers, employed by the organizations, in case they need any kind of help in accomplishing their everyday lives, such as help with dealing with authorities. Once a month all vendors, journalists and social workers come together for a staff meeting, in which they discuss problems regarding the selling of the newspaper.

The organizations in our context are socially tainted and stigmatized for two reasons. First, organizational outputs and routines involve contact with homeless people, who are themselves regarded as stigmatized. This formally taps the definition of social taint (Ashforth \& Kreiner, 1999; Hughes, 1951). Second, the stigma is pervasive because dealing with homeless people is central to the organizations' images and missions. As the organizations 
are primarily defined by serving or employing the homeless, they are consensually defined by the taint of homelessness. As a consequence, attributions of homelessness are likely to be highly salient to all frontline employees that are prototypical for their organization (Kreiner et al., 2006). In the present context this would mean that through signaling that a vendor is part of the organization, people often infer that he or she is homeless, as the mission of the organization is to employ the homeless as vendors. Ironically, however, roughly only one third of the vendors working for the organizations are actually homeless (as indicated by our conversations with organizational leaders). Corroborating evidence of this "courtesy stigma" and case of mistaken identity appeared in an article in the street newspaper that reported how a student interned with one of the organizations. The student dressed like a vendor and sold the street newspaper for one day. The student reported that after greeting potential customers, many of them greeted him back—but walked very quickly_and seemed to be distrustful of him, as if he were going to harm them in some way.

In line with Bamberger and Pratt (2010), the present organizational context represents an unconventional research setting and therefore provides some benefits over conventional settings. For instance, the pervasively stigmatized organizational background of our study provides conceptual fidelity and relational variance for testing stigmatization effects and thus, “facilitates the development of rich theory” (Bamberger \& Pratt, 2010, p. 668). Moreover, unconventional research settings have a long tradition in the organizational and management literature (e.g., Bechky \& Okhuysen, 2011; Dutton \& Dukerich, 1991; Elsbach \& Sutton, 1992; Hudson \& Okhuysen, 2009). That said, because of the widespread nature of stigma in organizational life, our findings are also ripe for transferability beyond this sample-a point we return to again in the Discussion.

For testing our hypotheses, the present context is ideal as it involves low-involvement frontline interactions. Thus, customers are likely to rely on stereotypes as cognitive short 
cuts. Because of the low-involvement situation, they lack motivation for processing individuated information, as this would generally tax more cognitive capacities (Wilder, 1993).

\section{Procedures and Sample}

Data sources. We acquired multiple-source data for our study. We collected data from vendors, data from trained observers who coded vendors’ prototypicality, as well as data from customers and noncustomers who observed sales encounters with these vendors. Data from the different sources were matched by using code numbers. Figure 1 depicts an overview of the different data sources for all focal constructs.

Trained observers. Prior to their assignment, all observers were trained during a 1-hr workshop in which we prepared them for interacting with the vendors and customers. We reviewed each component of the questionnaire, made sure that they understood the questions correctly, and instructed them on how to behave during their observation time (explained below) and how to collect the data. In particular, they were briefed and taught about the specific vendors' characteristics and behaviors that they were to monitor to assess vendors' organizational prototypicality. To assure that observers were able to assess vendors' organizational prototypicality, we gave observers a picture of a highly prototypical vendor (provided by the organization), and we shared behavioral examples of prototypicality (e.g., shouting out the name of the paper as people walked by, waving a small flag bearing the newspaper name, and/or wearing hats, jackets, shirts or pins bearing the name of the paper). This information directly reflect the essence of prototypicality - that prototypical boundary spanners signal the attributes, behaviors and orientations that are specific to the respective organization via verbal expressions, behaviors, dress or other tangibles to the customers (Ahearne et al., 2005; Bitner, 1990; Homburg et al., 2009; Latrofa et al., 2010; Sluss et al., 2012). Note that prototypicality here is in relation to the organization and not to the homeless 
population writ large. During at least $3 \mathrm{hr}$ that a single vendor was in the field, two trained observers were present. The observers were located approximately two yards away from the vendor such that they could be nonintrusive during the customer interaction yet still observe facial and other nonverbal behaviors. As the data collection took place on fairly busy urban streets, this positioning helped the data collection was unobtrusive during the potential sales interaction. Furthermore, during their time in the field the observers were instructed not to talk to the vendor. Also, because the vendors continually perform their jobs in such a busy, high-visibility context, they are already accustomed to being watched while they work. After they had spent at least three hours in the field with a given vendor, observers coded the vendor's attributes and behaviors on a questionnaire. We assigned two observers per vendor to ensure reliability of the observations. The final sample yielded 152 observations of 76 vendors (11 of whom were homeless).

Customers and noncustomers. Every customer of a vendor during the observation periods was asked to participate in the study by the trained observers after the person had bought a newspaper. Furthermore, every fifth noncustomer of a vendor who had visual contact with the vendor was selected by the observers and asked to participate. The final sample includes a total of 907 individuals (34\% overall response rate), comprising 297 customers (51\% response rate) and 610 noncustomers (29\% response rate).

Vendor. The questionnaires were personally administered to vendors by members of our research team to ensure proper administration. Vendors were asked to complete the questionnaires after members of our research team had spent at least three hours in the field with them. Before collecting data on a given vendor, they agreed that their customers and prospects could be asked for participation in the study; in return, vendors received free copies of newspapers (a few days after data collection).

\section{Measures}


The Appendix provides a list of the focal measurement items used in this study.

Prototypicality. Trained observers rated vendor's organizational prototypicality on a scale adopted from Jetten, Spears, and Manstead (1998). We calculated interrater agreement (refers to the equivalence of ratings) and interrater reliability (refers to the relative consistency in ratings). Specifically, we calculated the single-item rwg (James, Demaree, \& Wolf, 1984, 1993), which defines agreement in terms of the proportional reduction in error variance (LeBreton \& Senter, 2008), the single-item awg, which defines agreement as proportion to maximum possible disagreement (Brown \& Hauenstein, 2005), Kendall’s tau and two intraclass correlation coefficients, ICC(1) and ICC(2) (Bliese, 2000), which are a function of both absolute rater consensus and relative rater consistency (LeBreton \& Senter, 2008). Table 1 provides a full list of the interrater statistics. Results indicate high interrater agreement and reliability, thus justifying aggregation of ratings across observers. Cronbach’s alpha was .98 .

Insert Table 1 about here

Stereotypes. As stigma has been defined as belonging to a social category against which others collectively hold negative stereotypes (Crocker \& Major, 1989), we used negative stereotypes to operationalize the stigma. We based our approach on Gardner's (1994) stereotype differential technique, which is consistent with existing work in this area (Babin et al., 1995; Homburg, Wieseke, Lukas, \& Mikolon, 2011). We first conducted indepth interviews with 10 individuals who have interacted with vendors of street newspapers, using projective word association to generate a list of characteristics that are most associated with vendors of homeless-advocate street newspapers (most associated characteristics, or MACs). We then operationalized the MACs in the form of a statement and pretested them with a sample of 73 students. Next, we conducted statistical reduction procedures to determine those MACs that represent a stigma-related stereotype against vendors of street 
newspapers and used them to construct our stereotype scale. Cronbach’s alpha was .92. Accordingly, we measured vendors' metastereotypes with the same items that we used for customers' stereotypes. This is in line with previous research in social psychology that examines metastereotypes with well-accepted stereotype assessment procedures (e.g., Vorauer et al., 1998). Furthermore, this approach takes the theoretical notion into account that members of different groups have a shared understanding of the characteristics that are commonly associated with their own group by other social groups (Frey \& Tropp, 2006). Cronbach’s alpha was .88.

Outcomes. We determined customers' perceived quality of interaction using four items of Hartline and Ferrell's (1996) well-established scale that were suitable for the present context. Cronbach's alpha was .79. For customer rewards, we measured the extent of discretionary financial gains (tip sizes) received by the vendor (cf. Chi et al., 2011). For tracking individual customer's tip sizes, the observers tracked the actual price paid by a customer (the price varied, as customers were free to pay as much as they wanted as long as they paid the given minimum price). We then computed tip sizes subtracting the paid price from the minimum price.

Control variables. We controlled for multiple factors that can potentially influence our variables to rule out alternative explanations for our findings. To test whether boundary spanners' level of organizational identification is significantly related to their level of prototypicality for their organization (Ashforth \& Mael, 1989), we empirically tested this link in our model. We measured organizational identification with items from Mael and Ashforth’s (1992) well-established scale.

In predicting frontline workers’ organizational prototypicality, we controlled for their organizational tenure (for reviews, see Quiñones, Ford, \& Teachout, 1995; Sturman, 2003). Furthermore, it is reasonable to assume that their metastereotypes impact customer rewards. 
We therefore controlled for this link. We also controlled for customers' income in predicting customer rewards.

For separating the stigmatization effect that originates from the organizations from the effects that originate from vendors' personal social categories, we controlled for a series of variables that reflect vendors’ personal social categories. Specifically, we controlled for vendors’ age, gender, minority-group status and homelessness in predicting customers’ negative stereotypes. While we dummy-coded the variables gender and minority-group status $(0=$ males and 1 = females; 0 = foreign-nationality; 1 = home-nationality $)$, we assessed vendors' age with a corresponding item in the vendor questionnaire. The variable homelessness was dummy-coded ( $0=$ non-homeless; 1 = homeless). Furthermore, we kept occupational attributions constant as all of the focal frontline workers were newspaper vendors. We also controlled for customers’ demographics (age, gender, minority-group status). The variables gender and minority-group status were dummy-coded $(0=$ males and 1 = females; 0 = foreign-nationality; 1 = home-nationality).

Moreover, in predicting customers' negative stereotypes, we controlled for the type of exchange and for perceived onset controllability, which reflects perceived responsibility for a stigma (Florey \& Harrison, 2000), we controlled for perceived onset controllability in predicting customers' stereotypes toward the vendors. We assessed type of exchange based on existing taxonomies in the management and marketing literature (Gundlach \& Murphy, 1993; Gutek, Bhappu, Liao-Troth, \& Cherry, 1999) with a single item, "I always buy the newspaper from this particular vendor.” Customers could either agree or disagree with this statement. We then coded agreement as repeated exchange, coded with a “ 1 ” and disagreement as transactional exchange, coded with a “0.” This measurement draws from a common key element of existing conceptualizations of exchange types (Gundlach \& Murphy, 1993) and forms of service encounters (Gutek et al., 1999) — the time horizon of the 
exchange in the sense that transactional exchanges involve single interactions, whereas repeated exchanges involve multiple interactions over an extended time frame.

We measured perceived onset controllability using a single-item measure. We asked customers to rate the degree to which they believed that vendors are to blame for their difficult situation on a 7-point scale ranging from 1 (low degree) to 7 (high degree).

Although organizations that are primarily defined by employing or serving stigmatized groups or individuals become stigmatized themselves, people may also associate positive attributes with these organizations. Thus, we controlled for customers’ and noncustomers’ overall attitude toward the organizations, which we assessed with a single item, on which participants had to rate the extent to which they agreed to the following statement, "Overall, I have a positive opinion toward [organization].”

\section{Measurement Model}

The reliability of all reflective scales is sufficient, with Cronbach's alpha scores ranging from .72 to .98 . To evaluate the reflective scales, we conducted a confirmatory factor analysis. Although the chi-square statistic was significant, the comparative fit index, the standard rootmean-square residual and the root mean square error of approximation $(97, .033$, and .048, respectively) all indicate that the measurement model fits well. All factor loadings of the indicators on the respective latent constructs were significant. The values for the average variance extracted ranged from .50 to .95 . These results indicate that the employed reflective scales possess sufficient convergent and discriminant validity. Furthermore, all squared correlations between the latent constructs were smaller than the average variance extracted from the respective constructs, further supporting the measures’ discriminant validity (Fornell \& Larcker, 1981).

\section{Analytical Approach}


Given the hierarchical structure of the dataset, that is, customers (within level 1) are nested or clustered within frontline workers (between level 2), which are nested in two organizations, we used hierarchical linear modeling to test our hypotheses (Raudenbush \& Bryk, 2002). Nested data may yield similarity of responses within levels or clusters but variation between levels or clusters. In other words, the responses of customers' who dealt with one vendor might be more alike than they are from customers' who interacted with another vendor. Thus, in case of nested data, the independence of observations assumption of regression models is violated, which can result in underestimated standard errors (Maxham, Netemeyer, \& Lichtenstein, 2008).

For conducting our analyses we grand mean centered all metric explanatory variables (Kreft, de Leeuw, \& Aiken, 1995; Snijders \& Bosker, 1999) and estimated a multilevel path model using Mplus software (Version 7; L. Muthén \& Muthén, 1998-2012). Multilevel path models allow researchers to investigate more complex theoretical models that include multiple dependent variables than traditional multilevel regression models and to test all relationships simultaneously (Heck \& Thomas, 2009). While we explicitly modeled within level 1 and between level 2 because they are of theoretical interest for our investigation, we followed Geiser, Eid, Nussbeck, Courvoisier, \& Cole (2010) to handle the third (organizational) level. More specifically, we used robust ML estimation in which a so-called sandwich estimator is used to compute adjusted standard errors and test statistics to take into account nonindependence of observations due to third-level nestings (B. O. Muthén \& Muthén, 1998-2004; B. O. Muthén \& Satorra, 1995).

\section{Results}

Table 2 reports the means, standard deviations, and correlations coefficients of all study variables. 
After we fitted an unconditional (intercepts only) model, we ran a baseline model (Model 1) that simultaneously estimated all relationships on the between- and within-level, excluding the cross-level effects. In a next step, we also included the cross-level relationships to estimate our full hypothesized model (Model 2). Because standard fit indices are not available with the procedure used by Mplus to estimate random slope-effects, we employed a log-likelihood difference test to compare our models. Since the models were estimated using maximum likelihood estimation with robust standard errors, we corrected the values for the log-likelihood difference test, following the procedure proposed by Satorra and Bentler (2001). The log-likelihood difference test for Model 1 and 2 (-2 Log-likelihood-change 32.88, d.f. $=3, p \leq .01)$ confirms that the inclusion of the cross-level relationships leads to a significant increase in model fit, which substantiates the hypothesized cross-level links. Table 3 presents the results of the multilevel path model.

Insert Table 3 about here

Turning to testing our hypotheses, we begin with the between-level hypothesis. H2 predicts that frontline employees higher in organizational prototypicality will have stronger meta-stereotypes. Our results support H2, such that organizational prototypicality is positively associated with meta-stereotypes (H2, $b=.269, p \leq .05)$.

Turning to the within-level hypotheses, we find support for the hypothesized negative relationship between customers' negative stereotypes and their perceived quality of interaction (H3, $b=-.308, p \leq .01)$. Our results also confirm that perceived quality of interaction is positively associated with customer rewards (H5, $b=.096, p \leq .01)$.

Finally, our results lend support to both cross-level hypotheses. Specifically, we find a positive association between frontline employees’ organizational prototypicality and their customers' negative stereotypes $(b=.123, p \leq .01)$, as predicted by H1. Furthermore, we find that frontline workers’ meta-stereotypes significantly moderate the relationship between 
customers’ negative stereotypes and perceived quality of interaction as predicted in H4 ( $b=$ $.92, p \leq .01$ ). Thus, our results support the hypothesized stigma magnification effect. Figure 2 depicts the estimation results for the conceptualized model.

In order to facilitate interpretation of the stigma magnification effect, we plotted the relationship according to standard procedures (Aiken \& West, 1991). The plot is depicted in Figure 3. We calculated the significance of the simple slopes and found significant negative relationships between customers’ stereotypes and their perceived quality of interaction when frontline workers’ meta-stereotypes were high $(b=-.462, S E=.066, t=-7.041, p \leq .01$ for +1 s.d.) and when meta-stereotypes were low $(b=-.154, S E=.065, t=-2.380, p \leq .05$ for -1 s.d.). Insert Figure 3 about here

\section{Controls}

Although we controlled for multiple revelant covariates the link between vendors’ organizational prototypicality and customers’ stereotypes remained stable. Most notably, while we partialed out the stigmatization effect that originates from the vendors personal social categories, by controlling for vendors’ minority-group status, age, gender and homelessness ${ }^{1}$, we still find a robust link between vendors’ prototypicality and customers’ stereotypes. Overall, this supports our contention that the taint spills over from the organization to the individual frontline worker. Thus the stigma of homelessness is rendered salient in the mind of customers as a function of frontline workers' prototypicality with their organizations. The customers subsequently ascribe negative attributes such as criminal or dishonest to all the frontline workers as a function of their prototypicality for the organization

\footnotetext{
${ }^{1}$ Note that we additionally specified a model in which we also controlled for vendors' bad smell and the stigmatization effect that may arise because of perceived dissimilarity between vendors and customers (e.g., Fiske 1993) by controlling for age discrepancy, gender similarity between customers and vendors and similarity in minority-group status. When controlling for these additional covariates all hypothesized relationships remained stable.
} 
and irrespective of whether they are actually homeless or not. Thus, also those vendors that are not stigmatized in their own right share the stigma through being associated with the organization.

Finally, our results indicate that organizational identification is positively related to organizational prototypicality $(b=.267, p<.01)$, which suggests that frontline workers' organizational identification may well have instigated a process that have led them to become more prototypical for their organization (Ashforth et al., 2008). Given our finding that organizational prototypicality triggers customers’ stereotypes, vendors therefore at least in part instigate customers' stigmatization process themselves.

\section{Discussion}

Although interest in the phenomenon of stigma continues to rise in management studies, we have heretofore lacked solid empirical evidence about how stigmatization plays out in actual employee-customer interactions. This was largely due to the focus by past research on one of those parties at a time rather than taking a more complete, multiparty approach. In this study we move beyond existing unidirectional perspectives and integrate both the perceptions of the frontline worker and the customer into one model. Our results, based on a dataset including data from three different sources, reveal the pivotal role of organizational prototypicality in the transfer of a stigma. Furthermore, our findings demonstrate that cognitive processes (negative stereotypes and metastereotypes), which are associated with a stigma independently and jointly, both within and across individual levels of analysis (stigma magnification effect), taint customer-employee interactions. Therefore, a key contribution of this study is that the negative adverse effects of stigma in customeremployee interactions are actually coproduced by the stigma bearer and perceiver. Beyond that the present study makes further important theoretical and 
empirical contribution to the growing body of research investigating the phenomenon of stigma in organizational contexts, on which we elaborate after having discussed the transferability of our findings.

Although we specifically chose a vivid setting to test stigma dynamics, our findings are applicable beyond this sample. From that extreme sample, we can consider the transferability of the findings, that is, how our findings would have applicability in other contexts (Lincoln \& Guba, 1985). Indeed, there is ample empirical and conceptual evidence that the phenomenon of stigmatization investigated in our context is not unique or restricted to unconventional settings (for other examples of research on stigma in organizational contexts, see Ashforth \& Kreiner, 1999; Hudson, 2008; Hudson \& Okhuysen, 2009; Kreiner et al., 2006). More specifically, frontline workers can acquire a stigma from multiple categoriesfrom the organization they represent, from their occupation, or from their personal social categories (e.g., gender, disability, or ethnicity). Irrespective of the source of the stigma, the bearing of the stigma itself implies similar cognitive processes like those demonstrated in the present investigation. For instance, a unifying characteristic of all stigmatized categories, with which boundary spanners might become associated, is that they are at the receiving end of negative stereotypes (Devers et al., 2009). As such, the insights we have developed about how negative stereotypes and metastereotypes independently and jointly taint boundary spanning interactions should be transferable to other stigmatized frontline workers.

Likewise, our finding that a frontline worker's prototypicality for a stigmatized social category leads observers to assume that the focal frontline worker carries the negative stereotypical trait ascriptions of the category is essentially a general cognitive categorization mechanism that operates independently of the source of the stigma. Hence, our findings provide good evidence for understanding the general nature of interactions between frontline workers who carry a stigma and customers. 


\section{Theoretical Implications}

This study enriches our current understanding of stigma in several ways, particularly (though not exclusively) as it pertains to boundary spanning interactions. We contribute to the stigma literature by developing a new, integrated approach that sheds light on the dual-party mechanisms through which a stigma becomes salient and subsequently poisons customer employee interactions. This integrated approach helps us to move beyond previous work that treats stigma as unidirectional—that the processes of perceiving someone's stigma and feeling stigmatized are largely independent. By contrast, our new approach enables us to understand how the stigma phenomenon is related to perceptions of both frontline employees and customers. More specifically, by establishing empirically that frontline workers’ metastereotypes moderate the relationship between customers’ negative stereotypes and perceived quality of interaction (what we call the stigma magnification effect), we reveal that stigmatized frontline workers may reinforce negative stereotypes toward them. Thus, we uncover that the negative adverse effects of stigma in customer-employee interactions are actually coproduced by the stigma bearer and perceiver. It is interesting to note that because stereotypes can operate unconsciously, this magnification effect seems to occur without necessarily involving conscious intent of either or both parties involved.

Furthermore, the stigma magnification effect shows that the concept of metastereotypes is an important element of stigmatization that has previously been overlooked by research in the domain of applied psychology. In fact, our more holistic nomological framework of stereotypes, metastereotypes and prototypicality— constructs that had previously only been explored conceptually or even neglected by organizational scholars in stigma researchcould be employed by future scholars to study stigma more thoroughly.

In addition to these contributions, our study advances research on organizational stigma. Previous work in this domain has predominantly explored how stigmatization 
processes are evoked at the organizational level (e.g., Hudson, 2008; Hudson \& Okhuysen, 2009; Wiesenfeld et al., 2008). For instance, organizations can become stigmatized because of an unusual or anomalous event such as corporate scandal or, more typically, because they are disapproved for their core attributes such as routines or employees (Hudson, 2008; Hudson \& Okhuysen, 2009). Although previous work on organizational stigma has generally acknowledged that an organizational level stigma is contagious (Hudson \& Okhuysen, 2009; Wiesenfeld et al., 2008), for example, a corporate failure can evoke a category-based stigmatization process of all members of an organization, these studies have not considered prototypicality as a driver of stigmatization and have been conceptual or nonquantitative, creating a need for quantitative elaboration. From an applied psychological standpoint, a novel insight of our study, then, is that an organizational stigma can be transferred to the individual employee level as a function of organizational prototypicality. Our research thus reveals some of the implications of organizational stigma for employees and affiliates and provides an empirical conceptualization for the theoretical concept of stigma contagion. This finding also opens an important door into managing the triggers of stereotyping and stigmatization. Finally, although we have focused on an organizational stigma, organizational frontline workers can also acquire a stigma from sources such as their occupation, or their personal social categories. However, we would expect that irrespective of the source of the stigma, the link between prototypicality for a dubious category would result into boundary spanners' reflection of the respective stigma. The key implication of this link is that once a boundary spanner has become associated with any stigmatized category, as a function of being a prototypical exemplar for this category, he or she is believed to carry the focal category’s inferred negative attributes (Wiesenfeld et al., 2008). Still, a key difference between organizational stigma and stigma derived from other sources might be that the perception of organizational prototypicality can be altered or influenced more easily, unlike 
the more fixed characteristics (e.g., disability) of many stigmatized individuals. We therefore encourage future scholars to more deeply investigate the drivers rather than merely the outcomes of stigmatization at the individual level across the three distinct sources of stigma. Our finding that there are systematic as opposed to random differences in the activation of an organizational stigma in boundary spanning interactions can be viewed as a promising starting point for more comprehensive empirical investigations of the drivers of stigma in the management literature. Considering each of these contributions, this study addresses multiple important research gaps and advances the emerging research on stigma in the organizational literature.

\section{Limitations and Future Research}

Of course, limitations are an inherent part of any study. Herein we note limitations of our study and elaborate on avenues for future research. First, we have chosen an extreme case — homeless newspaper vendors — to better study underlying processes (Bamberger \& Pratt, 2010). But extreme cases can be challenged in terms of their generalizability to other contexts. Indeed, as noted by one of our reviewers, studying the vendors of homeless newspapers was both a strength and a weakness of the study. Future research can address this issue by exploring how these dynamics play out in other contexts and for other stereotypes (e.g., occupational or individual social category).

Second, our study provides empirical evidence that metastereotypes of stigmatized frontline workers magnify adverse effects of customers' negative stereotypes. Nevertheless, more detail is needed on the causal behavioral processes that underlay stigma magnification in the context of frontline interactions. These processes might be best observations of the trained observers that helped to facilitate the present investigation, it is likely that the stigma magnification occurred through verbal and nonverbal behaviors by the frontline workers indicating negative responses to the interaction with customers. Such behaviors included, but 
were not limited to negative verbal responses to the interaction increased fidgeting, or trial and error behaviors aimed at developing an understanding about which scripts should guide actions during interactions with customers and noncustomers to effectively avoid being stigmatized. Therefore, future research could draw from this anecdotal evidence to explore the behavioral underpinnings of stigma magnification in more depth.

Another plausible consequence of frontline workers' metastereotypes is that they try to overtly compensate for the anticipated negative evaluation by customers by, for example, showing opposite behaviors of what they anticipate negative stereotypes against them might include. If this assumption were to be true, the resulting behaviors may have been perceived by the customer as violating their negative stereotypical expectancies. Based on expectancy violation theory (Jussim, Coleman, \& Lerch, 1987), we therefore ruled out the possibility of a cubic and a quadratic link between customers' negative stereotypes and perceived quality of interaction (Jussim et al., 1987). However, we did not find evidence that expectancy violation theory is pertinent. A reason for this might be that the degree of impact of stereotypes on extreme evaluations depends on "whether targets act in ways that are stereotype-consistent, stereotypeinconsistent, or stereotype violations” (Bettencourt, Dill, Greathouse, Charlton, \& Mulholland, 1997, p. 272). Future research should therefore examine frontline workers’ behaviors that overtly violate the stereotype and show opposite behaviors of it.

Furthermore, future scholars may wish to investigate the role that self-stereotypes play in the stigma magnification effect, because our interest with this investigation was in exploring how "other”-based perceptions (stereotypes and metastereotypes) would interact. The key here is that stereotypes and metastereotypes share something very important in common - they both focus on what one group member in an interaction is thinking of another party. By contrast, that is not the case for self-stereotyping, because the construct focuses inward on what a person thinks of his or her own group (Vorauer et al., 1998), making 
metastereotypes rather than self-stereotypes most relevant to our study. However, although metastereotypes rather than selfstereotypes appear to be a key constituent element of the stigma magnification effect, self-stereotypes may well serve as an input to metastereotypes and seem ripe for future investigation.

Because virtually all organizations can become stigmatized because of an unusual or anomalous event such as corporate scandal (Hudson, 2008; Hudson \& Okhuysen, 2009), future research can examine how organizations can dilute the stigma of their boundary spanners through manipulating boundary spanners’ organizational prototypicality. Because our work was focused on short-term and low-involvement business interactions, we suggest that scholars explore how a stigma plays out in more complex and/or longer-term boundary spanning interactions.

Whereas we operationalized vendors’ stigma as organizationally based (because not all our vendors were homeless), as another avenue for future research, scholars can (a) further develop the typology of stigma sources and (b) empirically test their variable effects. Future work could tease out similarities and differences across these three sources of stigma (e.g., in the "stickiness" of each type of stigma, and which processes are most effective in countering the stigma). Indeed, a particularly compelling research path would be examining the stigma magnification effect for each source and the associated consequences thereof.

Finally, our framework could also be applied to research on boundary spanning behaviors within organizations — such as when members of one category of workers interface with members of another (e.g., Marrone, Tesluk, \& Carson, 2007). For instance, it would be interesting to investigate through the lens of our nomological framework such interactions as a white-collar worker interfacing with a bluecollar worker, or members of high performing teams interacting with low performing teams in the organization. In sum, our study offers a 
promising starting point for more comprehensive empirical investigations of stigma in the management literature.

\section{Managerial Implications}

Complementing the theoretical implications, the current study also holds insights for managers in organizations that the public considers as tainted. This study shows the high relevance of stigma for managers by linking it to frontline workers' discretionary financial gains, which reflect the amount of value that has been created for the customer. Given the detrimental impact, managers can benefit from tending to issues of stigma, stereotypes, and prototypicality.

Our results suggest that frontline workers’ prototypicality for a stigmatized organization renders salient a stigma in customer- employee interactions. Frontline workers can become prototypical for their organization because they merely comply with organizational rules that serve as standard for appropriate dress or behaviors during frontline encounters and/or because they have internalized the attributes, values, goals, or prototypical traits that they perceive to be central to the organization. Therefore, managers should use caution in fostering frontline workers' prototypicality when the organization or occupation carries a stigma.

Beyond these managerial implications, the stigma magnification effect suggests that the negative consequences of stereotypes on quality of interaction with a stigmatized frontline worker are contingent on their metastereotypes, such that the impact is most severe when metastereotypes are particularly strong. Our findings, then, suggest a novel way for alleviating the adverse consequences of stigma. Rather than trying to change customers' negative stereotypes, managers can apply a variety of techniques to help employees to cope with the stigma cast onto them by tackling their metastereotypes. To initially reduce metastereotypes, managers could implement perspective-taking training, in which frontline 
workers are meant to put themselves in their customers' position (Homburg, Wieseke, \& Bornemann, 2009). In addition, a profound way for frontline employees to address their customers’ negative stereotypes during customer-employee interactions is to actively confront them with the perceptions of taint, through what Ashforth et al. (2007) termed "confronting clients and the public.” A particularly effective way to do this could be to use humor such as self-deprecating comments because "humor represents a relatively nonthreatening means of confronting public (and client) stereotypes” (Ashforth et al., 2007, p. 161).

\section{Conclusion}

All-in-all, our results both shed new light on the complexities of tainted customeremployee interactions and clearly link stigmatization processes to frontline workers’ performance. Further, by discovering and documenting the stigma magnification effect, our work has shown the importance of simultaneously studying both the stigmatized and the stigmatizer. For it is only when we acknowledge this "seeing you seeing me” phenomenon that we can fully account for the effects of stereotypes and stigma on critical boundary spanning interactions. 


\section{References}

Abrams, D., \& Hogg, M. A. (2004). Metatheory: Lessons from social identity research. Personality and Social Psychology Review, 8, 98-106. doi:10.1207/s15327957pspr0802_2

Adams, J. (1976). The structure and dynamics of behavior in organizational boundary role. In M. D. Dunnette (Ed.), Handbook of industrial and organizational psychology (pp. 11751199). Chicago, IL: Rand McNally College Pub. Co.

Adkins, R. T., \& Swan, J. E. (1982). Improving the public acceptance of sales people through professionalization. Journal of Personal Selling \& Sales Management, 2, 32-38.

Ahearne, M., Bhattacharya, C. B., \& Gruen, T. (2005). Antecedents and consequences of customer-company identification: Expanding the role of relationship marketing. Journal of Applied Psychology, 90, 574-585. doi:10.1037/0021-9010.90.3.574

Aiken, L. S., \& West, S. G. (1991). Multiple regression: Testing and interpreting interactions. Newbury Park, CA: Sage Publications.

Ashforth, B. E., \& Humphrey, R. H. (1997). The ubiquity and potency of labeling in organizations. Organization Science, 8, 43-58. doi:10.1287/orsc.8.1.43

Ashforth, B. E., \& Kreiner, G. E. (1999). How can you do it? Dirty work and the challenge of constructing a positive identity. Academy of Management Review, 24, 413-434.

Ashforth, B. E., \& Mael, F. (1989). Social identity theory and the organization. Academy of Management Review, 14, 20-39. doi:10.5465/AMR.1989.4278999

Ashforth, B. E., Harrison, S. H., \& Corley, K. G. (2008). Identification in organizations: An examination of four fundamental questions. Journal of Management, 34, 325-374. doi:10.1177/0149206308316059

Ashforth, B. E., Kreiner, G. E., Clark, M. A., \& Fugate, M. (2007). Normalizing dirty work: Managerial tactics for countering occupational taint. Academy of Management Journal, 50, 149-174. doi:10.5465/AMJ.2007.24162092

Babin, B. J., Boles, J. S., \& Darden, W. R. (1995). Salesperson stereotypes, consumer emotions, and their impact on information processing. Journal of the Academy of Marketing Science, 23, 94-105. doi:10.1177/0092070395232002

Bamberger, P. A., \& Pratt, M. G. (2010). From the editors: Moving forward by looking back: Reclaiming unconventional research contexts and samples in organizational scholarship. Academy of Management Journal, 53, 665-671. doi:10.5465/AMJ.2010.52814357

Bechky, B. A., \& Okhuysen, G. A. (2011). Expecting the unexpected? How SWAT officers and film crews handle surprises. Academy of Management Journal, 54, 239-261. doi:10.5465/AMJ.2011.60263060

Biernat, M., \& Dovidio, J. F. (2000). Stigma and stereotypes. In T. F. Heatherton, R. E. Kleck, M. R. Hebl, \& J. G. Hull (Eds.), The social psychology of stigma (pp. 88-125). New York, NY: Guilford Press.

Bitner, M. J. (1990). Evaluating service encounters: The effects of physical surroundings and employee responses. Journal of Marketing, 54, 69-82. doi:10.2307/1251871

Blascovich, J., Mendes, W. B., Hunter, S. B., \& Lickel, B. (2000). Stigma, threat, and social interactions. In T. F. Heatherton, R. E. Kleck, M. R. Hebl, \& J. G. Hull (Eds.), The social psychology of stigma (pp. 307-333). New York, NY: Guilford Press. 
Bliese, P. D. (2000). Within-group agreement, non-independence, and reliability: Implications for data aggregation and analysis. In K. J. Klein \& S. W. J. Kozlowski (Eds.), Multilevel theory, research, and methods in organizations. Foundations, extensions, and new directions (pp. 349-381). San Francisco, CA: Jossey-Bass.

Branscombe, N. R., Ellemers, N., Spears, R., \& Doosje, B. (1999). The context and content of social identity threat. In N. Ellemers, R. Spears, \& B. Doosje (Eds.), Social identity. Context, commitment, content (pp.35-58). Oxford, UK: Blackwell Science.

Brewer, M. B. (2003). Intergroup relations (2nd ed). Mapping social psychology. Buckingham, UK: Open University Press.

Brickson, S. L., \& Brewer, M. B. (2001). Identity orientation and intergroup relations in organizations. In M. A. Hogg \& D. J. Terry (Eds.), Social identity processes in organizational contexts (pp. 49-66). Philadelphia, PA: Psychology Press.

Brown, R.D., \& Hauenstein, N.M.A. (2005). Interrater agreement reconsidered: An Alternative to the $\mathrm{r}_{\mathrm{wg}}$ Indices. Organizational Research Methods, 8, 165-184.

Chebat, J.C., \& Kollias, P. (2000). The impact of empowerment on customer contact employees' roles in service organizations. Journal of Service Research, 3, 66-81. doi:10.1177/109467050031005

Chi, N.W.; Grandey, A. A.; Diamond, J. A.; Krimmel, K. R. (2011). Want a tip? Service performance as a function of emotion regulation and extraversion. Journal of Applied Psychology, 96, 1337-1346. doi: 10.1037/a0022884

Cowart, K.O., \& Brady, M.K. (2014). Pleasantly plump: Offsetting negative obesity stereotypes for frontline service employees. Journal of Retailing, 90, 365-378.

Crocker, J., \& Major, B. (1989). Social stigma and self-esteem: The self-protective properties of stigma. Psychological Review, 96, 608-630. doi:10.1037/0033-295X.96.4.608

Crocker, J., Major, B., \& Steele, C. (1998). Social stigma. In D. T. Gilbert, S. T. Fiske, \& G. Lindzey (Eds.), The handbook of social psychology (4th ed., Vol.2, pp. 504-553). New York, NY: McGraw-Hill.

Crosby, L. A., Evans, K. R., \& Cowles, D. (1990). Relationship quality in services selling: An interpersonal influence perspective. Journal of Marketing, 54, 68-81. doi:10.2307/1251817

Devers, C. E., Dewett, T., Mishina, Y., \& Belsito, C. A. (2009). A general theory of organizational stigma. Organization Science, 20, 154-171. doi:10.1287/orsc.1080.0367

Devine, P. G., Evett, S. R., \& Vasquez-Suson, K. A. (1996). Exploring the interpersonal dynamics of intergroup contact. In R. M. Sorrentino \& E. T. Higgins (Eds.), Handbook of motivation and cognition: Foundations of social behaviour (Vol. 3, pp.423-464). New York, NY: Guilford Press.

Doucet, L. (2004). Service provider hostility and service quality. Academy of Management Journal, 47, 761-771. doi:10.2307/20159617

Dovidio, J. F. (2001). On the nature of contemporary prejudice: The third wave. Journal of Social Issues, 57, 829-849. doi:10.1111/0022-4537.00244

Dutton, J. E., \& Dukerich, J. M. (1991). Keeping an eye on the mirror: Image and identity in organizational adaptation. Academy of Management Journal, 34, 517-554. doi:10.2307/256405 
Elsbach, K. D., \& Sutton, R. I. (1992). Acquiring organizational legitimacy through illegitimate actions: A marriage of institutional and impression management theories. Academy of Management Journal, 35, 699-738. doi:10.2307/256313

Fiske, S. T. (1993). Social Cognition and Social Perception. Annual Reviews in Psychology, 44, 155-94.

Fiske, S. T. (1998). Stereotyping, prejudice, and discrimination. In D. T. Gilbert, S. T. Fiske, \& G. Lindzey (Eds.), The handbook of social psychology (4th ed., Vol. 2, pp. 357-411). New York, NY: McGraw-Hill

Florey, A. T., \& Harrison, D. (2000). Responses to informal accommodation requests from employees with disabilities: Multistudy evidence on willingness to comply. Academy of Management Journal, 43, 224-233.

Fornell, C., \& Larcker, D. F. (1981). Evaluating structural equation models with unobservable variables and measurement error. Journal of Marketing Research, 18, 39-50. doi:10.2307/3151312

Frey, F. E., \& Tropp, L. R. (2006). Being seen as individuals versus as group members: Extending research on metaperception to intergroup contexts. Personality and Social Psychology Review, 10, 265-280. doi:10.1207/s15327957pspr1003_5

Fyock, J., \& Stangor, C. (1994). The role of memory biases in stereotype maintenance. British Journal of Social Psychology, 33, 331-343. doi:10.1111/j.20448309.1994.tb01029.x

Gardner, R. C. (1994). Stereotypes as consensual beliefs. In M. P. Zanna \& J. M. Olson (Eds.), The psychology of prejudice: The Ontario symposium (Vol. 7., pp. 1-33). Hillsdale, NJ: Lawrence Erlbaum Associates.

Geiser, C., Eid, M., Nussbeck, F. W., Courvoisier, D. S., \& Cole, D. A. (2010). Analyzing true change in longitudinal multitrait-multimethod studies: Application of a multimethod change model to depression and anxiety in children. Developmental Psychology, 46, 2945 .

Goffman, E. (1963). Stigma: Notes on the management of spoiled identity. Englewood Cliffs, NJ: Prentice Hall.

Gundlach, G. T. \& Murphy, P. E. (1993). Ethical and legal foundations of relational marketing exchanges. Journal of Marketing, 57, 35-46.

Gutek, B. A., Bhappu, A. D., Liao-Troth, M. A., \& Cherry, B. (1999). Distinguishing between service relationships and encounters. Journal of Applied Psychology, 84, 218233.

Hartline, M. D., \& Ferrell, O. C. (1996). The management of customer-contact service employees: An empirical investigation. Journal of Marketing, 60, 52-70. doi:10.2307/1251901

Hartline, M. D., Maxham, J. G., \& McKee, D. O. (2000). Corridors of influence in the dissemination of customer-oriented strategy to customer contact service employees. Journal of Marketing, 64, 35-50. doi:10.1509/jmkg.64.2.35.18001

Hebl, M. R., \& Dovidio, J. F. (2005). Promoting the "social" in the examination of social stigmas. Personality and Social Psychology Review, 9, 156-182. doi:10.1207/s15327957pspr0902_4

Hebl, M. R., Tickle, J., \& Heatherton, T. F. (2000). Awkward moments in interactions 
between nonstigmatized and stigmatized individuals. In T. F. Heatherton, R. E. Kleck, M. R. Hebl, \& J.G. Hull (Eds.), The social psychology of stigma (pp. 275-306). New York, NY: Guilford Press.

Heck, R. H., \& Thomas, S. L. (2009). An introduction to multilevel modeling techniques (2nd ed). New York, NY: Routledge.

Hekman, D. R., Aquino, K., Owens, B. P., Mitchell, T. R., Schilpzand, P., \& Leavitt, K. (2010). An examination of whether and how racial and gender biases influence customer satisfaction. Academy of Management Journal, 53, 238-264. doi:10.5465/AMJ.2010.49388763

Hackman, J. R., \& Oldham, G.R. (1975). Development of the job diagnostic survey. Journal of Applied Psychology, 60, 159-70.

Herek, G. M., Capitanio, J. P., \& Widaman, K. F. (2002). HIV-related stigma and knowledge in the United States: Prevalence and trends, 1991-1999. American Journal of Public Health, 92, 371-377. doi:10.2105/AJPH.92.3.371

Hilton, J. L., \& von Hippel, W. (1996). Stereotypes. Annual Review of Psychology, 47, 237271. doi:10.1146/annurev.psych.47.1.237

Hogg M.A. (2003). Intergroup relations. In J. D. DeLamater (Ed.), Handbook of social psychology (pp. 479-501). New York, NY: Kluwer Academic/Plenum Publishers.

Hogg, M. A., \& Turner, J. C. (1987). Intergroup behavior, self-stereotyping, and the salience of social categories. British Journal of Social Psychology, 26, 325-340.

Hogg, M. A., \& Abrams, D. (1988). Social identifications: A social psychology of intergroup relations and group processes. London, UK: Routledge.

Hogg, M. A., \& Terry, D. J. (2000). Social identity and self-categorization processes in organizational contexts. Academy of Management Review, 25, 121-140. doi:10.5465/AMR.2000.2791606

Homburg, C., Wieseke, J., \& Bornemann, T. (2009). Implementing the Marketing concept at the employee-customer interface: The role of customer need knowledge. Journal of Marketing, 73, 64-81. doi:10.1509/jmkg.73.4.64

Homburg, C., Wieseke, J., \& Hoyer, W. D. (2009). Social identity and the service-profit chain. Journal of Marketing, 73, 38-54. doi:10.1509/jmkg.73.2.38

Homburg, C., Wieseke, J., Lukas, B. A., \& Mikolon, S. (2011). When salespeople develop negative headquarters stereotypes: performance effects and managerial remedies. Journal of the Academy of Marketing Science, 39, 664-682. doi:10.1007/s11747-010-0233-2

Hudson, B. A. (2008). Against all odds: A consideration of core-stigmatized organizations. Academy of Management Review, 33, 252-266. doi:10.5465/AMR.2008.27752775

Hudson, B. A., \& Okhuysen, G. A. (2009). Not with a ten-foot pole: Core stigma, stigma transfer, and improbable persistence of men's bathhouses. Organization Science, 20, 134153. doi: $10.1287 /$ orsc. 1080.0368

Hughes, E. C. (1951). Work and the self. In J. H. Rohrer \& M. Sherif (Eds.), Social psychology at the crossroads (pp. 313-323). New York, NY: Harper and Brothers.

James, L. R., Demaree, R. G., \& Wolf, G. (1984). Estimating within-group interrater reliability with and without response bias. Journal of Applied Psychology, 69, 85-98. doi:10.1037/0021-9010.69.1.85 
James, L. R., Demaree, R. G., \& Wolf, G. (1993). An assessment of within-group interrater agreement. Journal of Applied Psychology, 78, 306-309. doi:10.1037/0021-9010.78.2.306

Jetten, J., Spears, R., \& Manstead, Antony S. R. (1998). Defining dimensions of distinctiveness: Group variability makes a difference to differentiation. Journal of Personality and Social Psychology, 74, 1481-1492. doi:10.1037/0022-3514.74.6.1481

Jost, J. T., \& Banaji, M. R. (1994). The role of stereotyping in system-justification and the production of false consciousness. British Journal of Social Psychology, 33, 1-27. doi:10.1111/j.2044-8309.1994.tb01008.x

King, E. B., Shapiro, J. R., Hebl, M. R., Singletary, S. L., \& Turner, S. (2006). The stigma of obesity in customer service: A mechanism for remediation and bottom-line consequences of interpersonal discrimination. Journal of Applied psychology, 91, 579-593. doi:10.1037/0021-9010.91.3.579

Kleck, R. E., \& Strenta, A. (1980). Perceptions of the impact of negatively valued physical characteristics on social interaction. Journal of Personality and Social Psychology, 39, 861-873. doi:10.1037/0022-3514.39.5.861

Kreft, I. G. G., de Leeuw, J., \& Aiken, L. (1995). The effect of different forms of centering in hierarchical linear models. Multivariate Behavioral Research, 30, 1-22.

Kreiner, G. E., Ashforth, B. E., \& Sluss, D. M. (2006). Identity dynamics in occupational dirty work: Integrating social identity and system justification perspectives. Organization Science, 17, 619-636. doi:10.1287/orsc.1060.0208

Krueger, J. I., Hall, J. H., Villano, P., \& Jones, M. C. (2008). Attribution and categorization effects in the representation of gender stereotypes. Group Processes \& Intergroup Relations, 11, 401-414. doi:10.1177/1368430208092542

Latrofa, M., Vaes, J., Cadinu, M., \& Carnaghi, A. (2010). The cognitive representation of self-stereotyping. Personality and Social Psychology Bulletin, 36, 911-922. doi:10.1177/0146167210373907

LeBreton, J. M., \& Senter, J. L. (2008). Answers to 20 questions about interrater reliability and interrater agreement. Organizational Research Methods, 11, 815-852. doi:10.1177/1094428106296642

Lee, N., Sandfield, A., \& Dhaliwal, B. (2007). An empirical study of salesperson stereotypes amongst UK students and their implications for recruitment. Journal of Marketing Management, 23, 723-744. doi:10.1362/026725707X230018

Lincoln, Y. S., \& Guba, E. (1985). Naturalistic inquiry. Beverly Hills: Sage.

Ma, Z., \& Dubé, L. (2011). Process and outcome interdependency in frontline service encounters. Journal of Marketing, 75, 83-98. doi:10.1509/jmkg.75.3.83

Macrae, C. N., \& Bodenhausen, G. V. (2000). Social cognition: Thinking categorically about others. Annual Review of Psychology, 51, 93-120. doi:10.1146/annurev.psych.51.1.93

Macrae, C., Stangor, C., \& Milne, A. B. (1994). Activating social stereotypes: A functional analysis. Journal of Experimental Social Psychology, 30, 370-389. doi:10.1006/jesp.1994.1018

Mael, F., \& Ashforth, B. E. (1992). Alumni and their alma mater: A partial test of the reformulated model of organizational identification. Journal of Organizational Behavior, 13, 103-123. doi:10.1002/job.4030130202 
Major, B., \& Crocker, J. (1993). Social stigma: The consequences of attributional ambiguity. In D. M. Mackie \& D. L. Hamilton (Eds.), Affect, cognition, and stereotyping: Interactive processes in group perception (pp. 345-370). San Diego, CA: Academic Press.

Major, B., \& O'Brien, L. T. (2005). The social psychology of stigma. Annual Review of Psychology, 56, 393-421. doi:10.1146/annurev.psych.56.091103.070137

Marrone, J. A., Tesluk, P. E., \& Carson, J. B. (2007). A multilevel investigation of antecedents and consequences of team member boundary-spanning behavior. Academy of Management Journal, 50, 1423-1439. doi:10.5465/AMJ.2007.28225967

Maxham, J. G., Netemeyer, R. G., \& Lichtenstein, D. R. (2008). The retail value chain: Linking employee perceptions to employee performance, customer evaluations, and store performance. Marketing Science, 27, 147-167. doi:10.1287/mksc.1070.0282

Méndez, E., Gómez, Á., \& Tropp, L. R. (2007). When metaperceptions are affected by intergroup processes. International Journal of Psychology and Psychological Therapy, 7, 237-250.

Muthén, L., \& Muthén, B. (1998-2012). Mplus User’s Guide. Seventh Edition. Los Angeles, CA: Muthén \& Muthén.

Muthén, B. O. (1998-2004). Mplus technical appendices. Los Angeles, CA: Muthén \& Muthén.

Muthén, B. O., \& Satorra, A. (1995). Complex sample data in structural

equation modeling. In P. V. Marsden (Ed.), Sociological methodology (pp. 267-316). Washington, DC: American Sociological Association

Paetzold, R. L., Dipboye, R. L., \& Elsbach, K. D. (2008). A new look at stigmatization in and of organizations. Academy of Management Review, 33, 186-193. doi:10.5465/AMR.2008.27752576

Parasuraman, A., Zeithaml, V. A., \& Berry, L. L. (1988). SERVQUAL: A multiple-item scale for measuring consumer perceptions of service quality. Journal of Retailing, 64, 12 40.

Pryor, J. B., Reeder, G. D., Monroe, A. E., \& Patel, A. (2010). Stigma and pro-social behavior; Are people reluctant to help stigmatized persons? In S. Stürmer \& M. Snyder (Eds.), Psychology of Helping: New Directions in Intergroup Prosocial Behavior (pp. 5980). London, UK: Blackwell.

Quiñones, M. A., Ford, J. K., \& Teachout, M. S. (1995). The relationship between work experience and job performance: a conceptual and meta-analytic review. Personnel Psychology, 48, 887-910. doi:10.1111/j.1744-6570.1995.tb01785.x

Raudenbush, S. W., \& Bryk, A. S. (2002). Hierarchical linear models: Applications and data analysis methods (2nd ed). Thousand Oaks, CA: Sage Publications.

Satorra, A., \& Bentler, P. M. (2001). A scaled difference chi-square test statistic for moment structure analysis. Psychometrika, 66, 507-514. doi:10.1007/BF02296192

Schaller, M., \& Conway, L. G. (1999). Influence of Impression-Management goals on the emerging contents of group stereotypes: Support for a social-evolutionary process.

Personality and Social Psychology Bulletin, 25, 819-833. doi:10.1177/0146167299025007005

Sluss, D. M., Ployhart, R. E., Cobb, M. G., \& Ashforth, B. E. (2012). Generalizing 
newcomers' relational and organizational identifications: Processes and prototypicality. Academy of Management Journal, 55, 949-975. doi:10.5465/amj.2010.0420

Snijders, T. A. B., \& Bosker, R. J. (1999). Multilevel analysis: An introduction to basic and advanced multilevel modeling. London: Sage.

Solomon, M. R., Surprenant, C., Czepiel, J. A., \& Gutman, E. G. (1985). A role theory perspective on dyadic interactions: The service encounter. Journal of Marketing, 49, 99111. doi: $10.2307 / 1251180$

Spears, R., Doosje, B., \& Ellemers, N. (1997). Self-stereotyping in the face of threats to group status and distinctiveness: The role of group identification. Personality and Social Psychology Bulletin, 23, 538-553. doi:10.1177/0146167297235009

Stangor, C., \& Crandall, C. S. (2000). Threat and the social construction of stigma. In T. F. Heatherton, R. E. Kleck, M. R. Hebl, \& J. G. Hull (Eds.), The social psychology of stigma (pp. 62-87). New York, NY: Guilford Press.

Steele, C. M. (1997). A threat in the air: How stereotypes shape intellectual identity and performance. American Psychologist, 52, 613-629. doi:10.1037/0003-066X.52.6.613

Sturman, M. C. (2003). Searching for the inverted u-shaped relationship between time and performance: Meta-analyses of the experience/performance, tenure/performance, and age/performance relationships. Journal of Management, 29, 609-640. doi:10.1016/S01492063_03_00028-X

Szymanski, D. M. (1988). Determinants of selling effectiveness: The importance of declarative knowledge to the personal selling concept. Journal of Marketing, 52, 64-77.

Van Kleef, G.A., Steinel, W., \& Homan, A. C. (2013). On being peripheral and paying attention : Prototypicality and information processing in intergroup conflict. Journal of Applied Psychology, 98, 63-79.

van Knippenberg, A., \& Dijksterhuis, A. (2000). Social categorization and stereotyping: A functional perspective. European Review of Social Psychology, 11, 105-144. doi:10.1080/14792772043000013

Vergne, J.-P. (2012). Stigmatized categories and public disapproval of organizations: A mixed-methods study of the global arms industry, 1996-2007. Academy of Management Journal, 55, 1027-1052. doi:10.5465/amj.2010.0599

Vorauer, J. D., Hunter, A. J., Main, K. J., \& Roy, S. A. (2000). Meta-stereotype activation: Evidence from indirect measures for specific evaluative concerns experienced by members of dominant groups in intergroup interaction. Journal of Personality and Social Psychology, 78, 690-707. doi:10.1037/0022-3514.78.4.690

Vorauer, J. D., Main, K. J., \& O'Connell, G. B. (1998). How do individuals expect to be viewed by members of lower status groups? Content and implications of meta-stereotypes. Journal of Personality and Social Psychology, 75, 917-937.

Voss, C. A., Roth, A. V., Rosenzweig, E. D., Blackmon, K., \& Chase, R. B. (2004). A tale of two countries' conservatism, service quality, and feedback on customer satisfaction. Journal of Service Research, 6, 212-230. doi:10.1177/1094670503260120

Warren, D. E. (2007). Corporate scandals and spoiled identities: How organizations shift stigma to employees. Business Ethics Quarterly, 17, 477-496. doi:10.5840/beq200717347

Wentzel, D. (2009). The effect of employee behavior on brand personality impressions and brand attitudes. Journal of the Academy of Marketing Science, 37, 359-374. 
doi:10.1007/s11747-009-0140-6

Wiesenfeld, B. M., Wurthmann, K. A., \& Hambrick, D. C. (2008). The stigmatization and devaluation of elites associated with corporate failures: A process model. Academy of Management Review, 33, 231-251. doi:10.5465/AMR.2008.27752771

Wilder, D. A. (1993). The role of anxiety in facilitating stereotypic judgment of out-group behavior. In D. M. Mackie \& D. L. Hamilton (Eds.), Affect, cognition, and stereotyping. Interactive processes in group perception (pp. 87-109). San Diego, CA: Academic Press. 
TABLE 1

Interrater Agreement and Interrater Reliability

\begin{tabular}{llllll}
\hline \multicolumn{1}{l}{} & & & & $\begin{array}{c}\text { Kendall’s } \\
\text { Tau }\end{array}$ \\
\hline Vendors' Organizational Prototypicality & ICC(1) & & & & \\
\hline 1. The vendor is a typical vendor of [organization's name]. & .851 & .920 & .859 & .925 & .775 \\
2. The vendor is similar to other [organization's name] vendors. & .820 & .901 & .831 & .917 & .698 \\
3. The vendor has a lot in common with [organization's name]. & .821 & .902 & .837 & .919 & .682 \\
4. The vendor is a good example of [organization's name]. & .832 & .908 & .841 & .914 & .749 \\
\hline
\end{tabular}


TABLE 2

Means, Standard Deviations,

and Scale Intercorrelations Among Study Variables

\begin{tabular}{|c|c|c|c|c|c|c|c|c|c|c|c|c|c|c|c|c|c|c|c|c|}
\hline Variable & M & SD & 1 & 2 & 3 & 4 & 5 & 6 & 7 & 8 & 9 & 10 & 11 & 12 & 13 & 14 & 15 & 16 & 17 & 18 \\
\hline 1. Org. prototypicality & 2.92 & 1.71 & - & & & & & & & & & & & & & & & & & \\
\hline 2. Metastereotypes & 2.86 & 1.67 & $.34 * *$ & - & & & & & & & & & & & & & & & & \\
\hline 3. Perc. quality of interaction & 5.35 & 1.06 & $-.33 * *$ & $-.40 * *$ & - & & & & & & & & & & & & & & & \\
\hline 4. Stereotypes & 3.07 & 1.14 & $.41^{* *}$ & $.39 * *$ & $-.42 * *$ & - & & & & & & & & & & & & & & \\
\hline 5. Customer rewards & 0.58 & 0.53 & .03 & $-.22 *$ & $.22 * *$ & -.05 & - & & & & & & & & & & & & & \\
\hline 6. Attitude toward the organization & 4.62 & 1.69 & $-.49 * *$ & $-.29 * *$ & $.48^{* *}$ & $-.34 * *$ & .10 & - & & & & & & & & & & & & \\
\hline 7. Customer age & 38.70 & 17.27 & -.15 & $-.32 * *$ & $.26 * *$ & $-.24 * *$ & .04 & $.28 * *$ & - & & & & & & & & & & & \\
\hline 8. Customer gender & 0.50 & 0.50 & -.17 & -.01 & $.07^{*}$ & $-.14^{* *}$ & .05 & .04 & .01 & - & & & & & & & & & & \\
\hline 9. Customer minority-group status & 0.04 & 0.19 & .05 & .09 & $-.19 * *$ & $.23 * *$ & -.07 & $.12 * *$ & $-.17 * *$ & $-.10 *$ & - & & & & & & & & & \\
\hline 10. Customer income & 2.80 & 1.27 & $-.28^{*}$ & -.16 & $.17 * *$ & $-.15^{* *}$ & $.19 * *$ & $.22 * *$ & $.43^{* *}$ & .00 & $-.08^{*}$ & - & & & & & & & & \\
\hline 11. Homelessness & 0.15 & 0.36 & .11 & .12 & -.16 & .11 & $-.22 *$ & -.21 & -.16 & .00 & .17 & -.06 & - & & & & & & & \\
\hline 12. Perc. onset controllability & 3.58 & 1.23 & $.30 * *$ & $.31^{* *}$ & $-.10 * *$ & $.18^{* *}$ & -.12 & .03 & $-.07 *$ & $-.10 * *$ & .06 & -.06 & .11 & - & & & & & & \\
\hline 13. Org. identification & 5.77 & 1.32 & $.37 * *$ & .08 & $-.28 *$ & $.24^{*}$ & -.06 & -.07 & -.12 & -.20 & -.08 & $-.36 * *$ & -.08 & .01 & - & & & & & \\
\hline 14. Org. tenure & 4.96 & 4.41 & $.23 *$ & -.09 & .07 & -.12 & -.04 & -.04 & .02 & -.02 & -.02 & .09 & -.02 & .05 & -.02 & - & & & & \\
\hline 15. Type of exchange & 0.23 & 0.19 & $-.31 * *$ & $-.29 * *$ & $.23^{* *}$ & $-.17 * *$ & .08 & $.29 * *$ & $.36 * *$ & .07 & $-.11^{*}$ & $.25 * *$ & -.09 & -.06 & .03 & .06 & - & & & \\
\hline 16. Vendor age & 44.16 & 12.14 & -.05 & -.21 & .17 & $-.35 * *$ & .03 & .12 & .18 & .04 & -.08 & .07 & -.14 & .04 & -.10 & $.29 *$ & .13 & - & & \\
\hline 17. Vendor gender & 0.32 & 0.47 & -.20 & -.19 & $.28^{*}$ & .11 & .08 & .15 & .03 & .14 & .13 & -.08 & -.08 & .01 & .08 & -.08 & -.01 & -.09 & - & \\
\hline 18. Vendor minority-group status & 0.15 & 0.35 & -.08 & .08 & -.01 & $.35^{* *}$ & -.04 & -.12 & -.02 & -.10 & -.10 & .15 & -.17 & -.12 & $.36^{* *}$ & $-.38 * *$ & .03 & $-.40 * *$ & $.28 *$ & - \\
\hline
\end{tabular}


TABLE 3

Estimates and Path Coefficients of the Multilevel Path Model

Relationships

Model 1

Model $2^{\mathrm{b}}$

Between-Level-Hypothesis

Org. prototypicality $\rightarrow$ Metastereotypes $\left(\mathrm{H}_{2}\right)$

$.269(.107)^{*}$

$.269(.107)^{*}$

Within-Level-Hypotheses

Negative stereotypes $\rightarrow$ Perc. quality of interaction $\left(\mathrm{H}_{3}\right)$

Perc. quality of interaction $\rightarrow$ Customer rewards $\left(\mathrm{H}_{5}\right)$

Cross-Level-Hypotheses

Org. prototypicality $\rightarrow$ Negative stereotypes $\left(\mathrm{H}_{1}\right)$

Metastereotypes x Stereotypes $\rightarrow$ Perc. quality of interaction $\left(\mathrm{H}_{4}\right)$

Covariates

Org. identification $\rightarrow$ Org. prototypicality

Org. tenure $\rightarrow$ Org. prototypicality

Attitude toward the organization $\rightarrow$ Negative stereotypes

Customer age $\rightarrow$ Negative stereotypes

Customer gender $\rightarrow$ Negative stereotypes

Customer minority-group status $\rightarrow$ Negative stereotypes

Vendor age $\rightarrow$ Negative stereotypes

Vendor gender $\rightarrow$ Negative stereotypes

Vendor minority-group status $\rightarrow$ Negative stereotypes

Onset controllability $\rightarrow$ Negative stereotypes

Type of exchange $\rightarrow$ Negative stereotypes

Attitude toward the Organization $\rightarrow$ Perc. quality of interaction

$-.328(.049)^{* *}$

$-.308(.050)^{* *}$

$.097(.027)^{* *}$

$.096(.027)^{* *}$

Metastereotypes $\rightarrow$ Perc. quality of interaction

Customer income $\rightarrow$ Customer rewards ${ }^{\mathrm{a}}$

Homelessness $\rightarrow$ Customer rewards ${ }^{\mathrm{a}}$

$\begin{array}{cc}- & .123(.040)^{* *} \\ & -.092(.027)^{* *} \\ & \\ .267(.056)^{* *} & .267(.056)^{* *} \\ .059(.026)^{*} & .059(.026)^{*} \\ -.159(.021)^{* *} & -.156(.021)^{* *} \\ -.006(.002)^{*} & -.006(.002)^{*} \\ -.116(.064) & -.114(.064) \\ .667(.314)^{*} & .670(.310)^{*} \\ -.005(.003) & -.004(.003) \\ -.101(.090) & -.082(.088) \\ .522(.211)^{*} & .573(.216)^{* *} \\ .130(.031)^{* *} & .127(.031)^{* *} \\ -.073(.066) & -.065(.067) \\ .208(.024)^{* *} & .216(.024)^{* *} \\ -.128(.032)^{* *} & -.105(.033)^{* *} \\ .095(.036)^{* *} & .091(.036)^{*} \\ -.145(.065)^{*} & -.145(.065)^{*}\end{array}$

Increase in Model Fit (Satorra \& Bentler, 2001)

-2 Log-likelihood change

$32.88(\text { d.f. }=3)^{* *}$

Note. ${ }^{* *} p \leq .01,{ }^{*} p \leq .05$. The table shows unstandardized coefficients (SE). In all hypothesized relationships, we controlled for homelessness of the vendors We solely report the only significant effect for this covariate in the table.

${ }^{2}$ The estimation of this effect is based on $n=297$ within-level subjects (customers only) as noncustomers did not pay any price.

We al so tested a version of Model 2 in which we additionally controlled for vendors' age, gender, minority-group status and job satisfaction as well as

customers' perceived onset controllability and type of exchange in predicting customers' perceived quality of interaction and for metastereotypes and negative stereotypes in predicting customer rewards and found that results for the hypothesized relationships remained stable. 
FIGURE 2

Estimation Results for the Conceptual Model

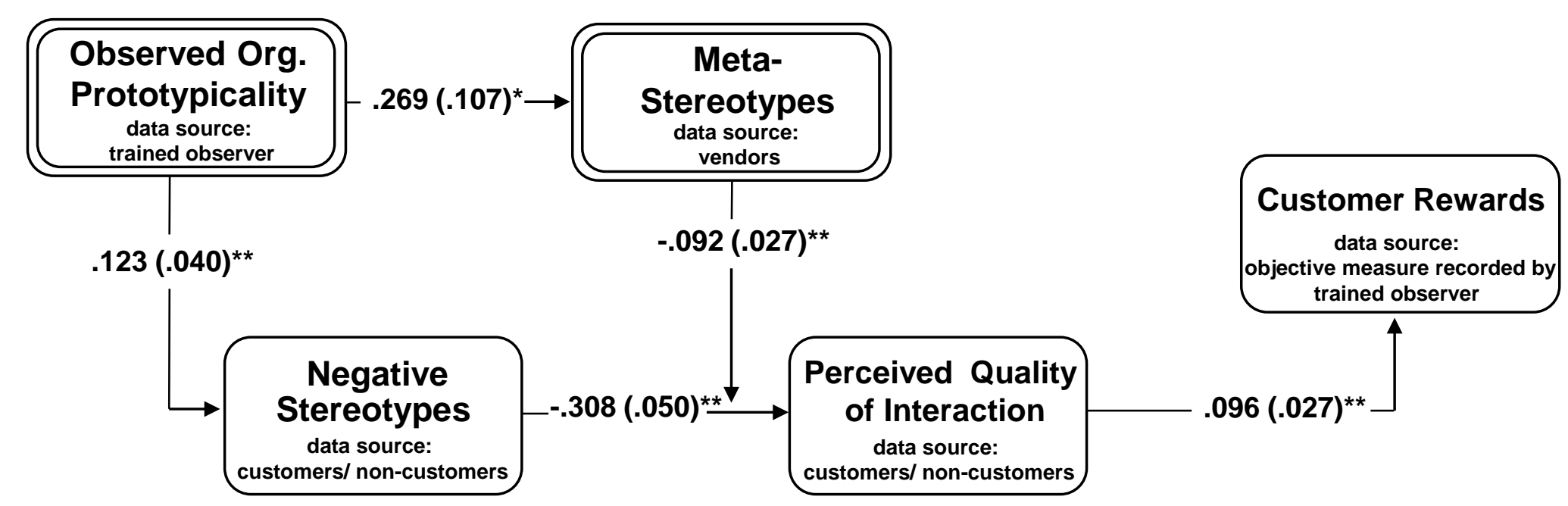

Frontline Worker-Level (Vendors)

Customer-Level

Estimation results for the conceptual model. The table shows unstandardized coefficients (SE). Note that we also tested a version of Model 2 (see Table 3) in which we additionally controlled for vendors' age, gender, minority-group status and job satisfaction as well as customers' perceived onset controllability, and type of exchange in predicting customers' perceived quality of interaction and for metastereotypes and negative stereotypes in predicting customer rewards and found that results for the hypothesized relationships remained stable. Further control variables measured at the vendor-level include homelessness of the vendors, vendors' age, gender, minority-group status, organizational identification, and organizational tenure. 
FIGURE 3

Stigma Magnification Effect

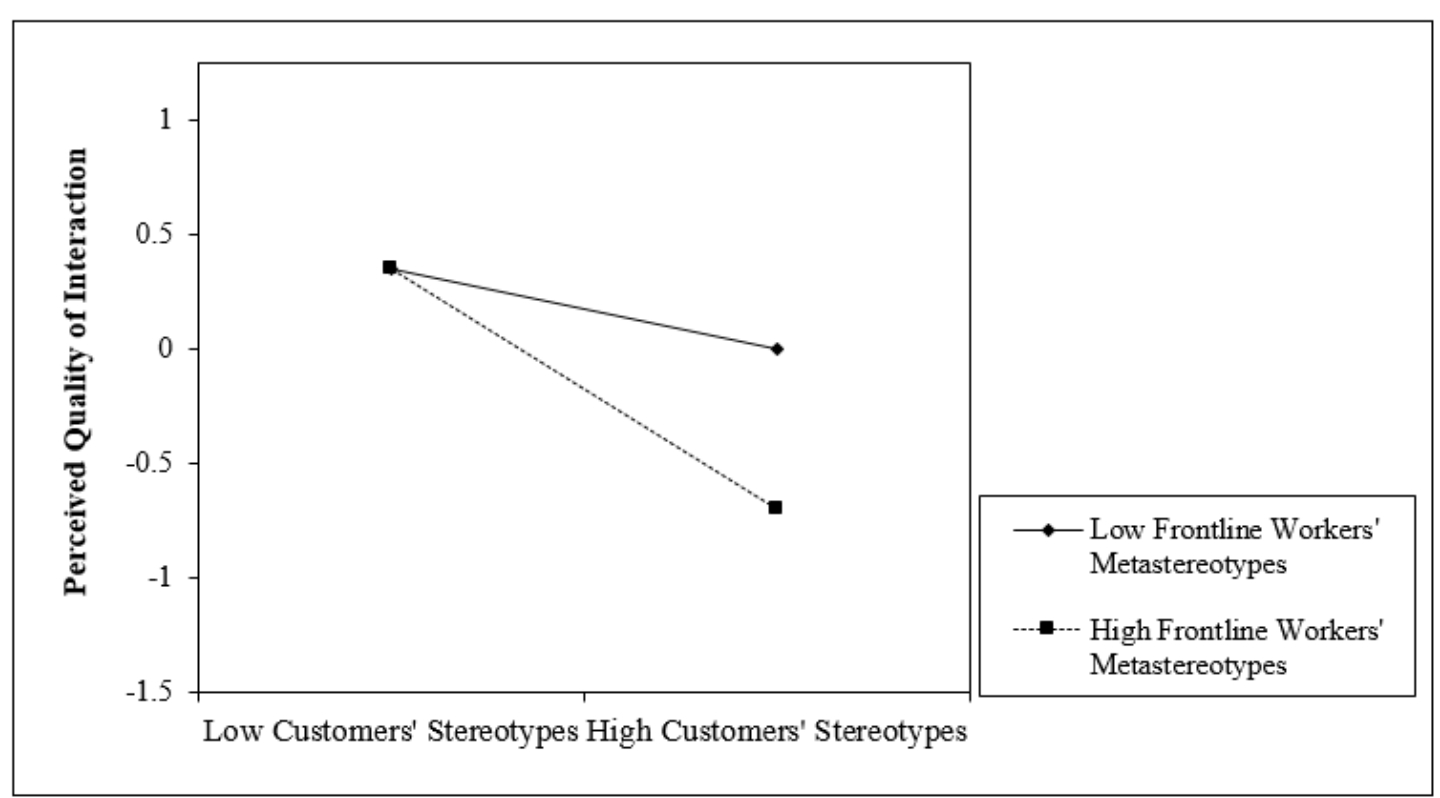

